\title{
Research on the Teaching Reform and Practice of Product Design Course Xiao-na $\mathrm{Yu}^{1}$, Xiang-shuo $\mathrm{He}^{2}$, Li-feng Zhang ${ }^{3}$ \\ ${ }^{1}$ North China Electric Power University Science \& Technology College, Baoding, China \\ ${ }^{2}$ North China Electric Power University, Baoding, China \\ ${ }^{3}$ Engineering Consulting Co. Ltd., CARS, Beijing, China
}

Keywords: Product design, Innovative ability, Teaching method, Data base

\begin{abstract}
The reform of the methods of product design of industrial design specialty and program course concentrates on cultivating students' innovative ability. When it comes to the teaching contents, it introduces programs from enterprise design competition and organizes the teaching according to the methods of product design in the enterprises. As to the teaching methods, it applies case teaching and establishes seminars. To improve the assessment, procedural ideals and network evaluation methods are introduced. Teaching resources base, which contains the idea of integral ware, includes digital component that is convenient for students to divide, reconstruct and reuse. This way can not only present the hierarchy structured system of the teaching contents, but also contribute to realizing individual learning and cultivating students’ divergent thinking and innovative ability.
\end{abstract}

\section{Introduction}

The course of "Product design method and procedure" is the main professional basic course of industrial design major [1]. It mainly introduces the principle of product design, such as scope, object, characteristic, product design thinking, function and form, various methods and design procedures of product design, which is to explore the design of cognitive, design law and research methods [2]. Based on the theory and practice teaching for more than ten years, we take improving the students' product design innovation ability as the starting point, regarding the design method and design flow as the main line, and fostering students' innovation ability as the goal, in order to carry out research and try to reform teaching contents and methods. This paper includes the following four sections which are shown in Fig. 1.

\section{Carefully Organize the Teaching Content}

It emphasizes that the theory and method of product design is seen as the guide and the product design practice as the center. At the various stages of the course teaching, we carefully organize the corresponding design theory knowledge and arrange the design practice topic reasonably. The students can innovate in the learning process of these stages [3]. Awareness has been fully cultivated, innovation ability can be improved, hand-painted, computer-aided design, integrated design and creativity have been continuously strengthened. We have been practicing teaching interaction, financial education, learning in the design process. 


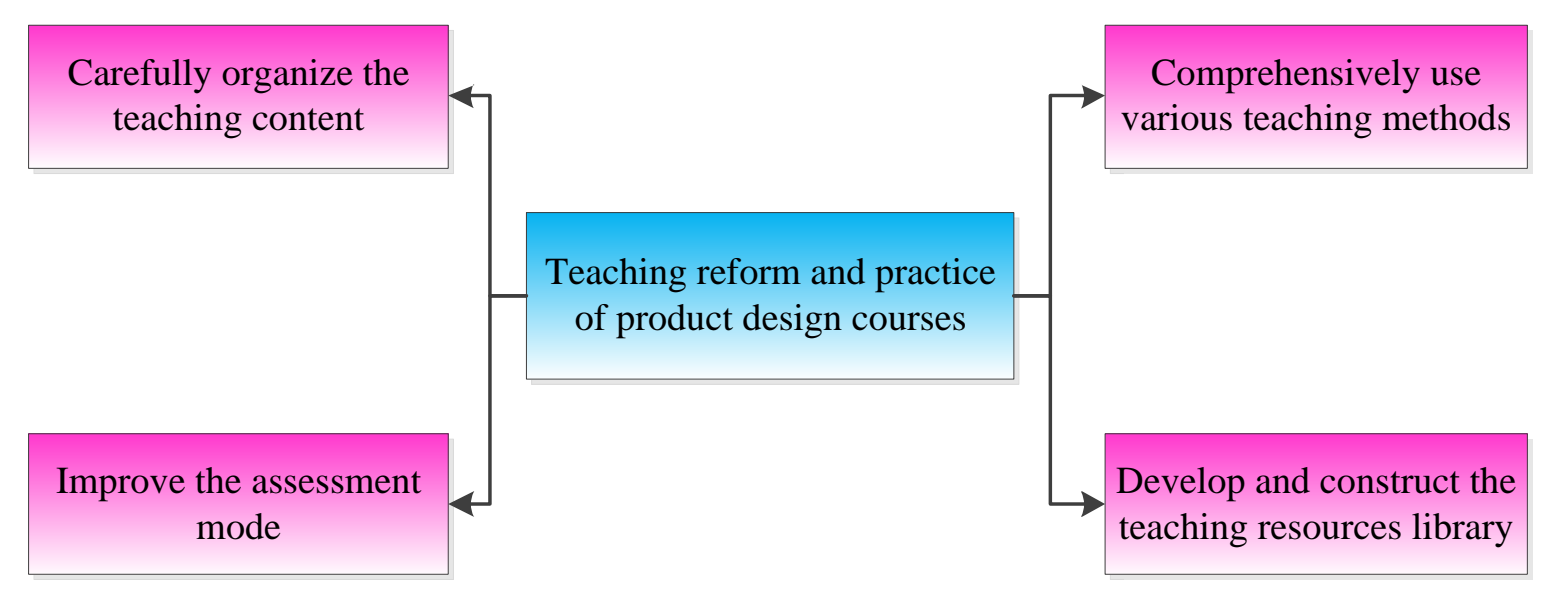

Fig. 1 The main structure of this paper

It emphasizes that the theory and method of product design is seen as the guide and the product design practice as the center. At the various stages of the course teaching, we carefully organize the corresponding design theory knowledge and arrange the design practice topic reasonably. The students can innovate in the learning process of these stages. Awareness has been fully cultivated, innovation ability can be improved, hand-painted, computer-aided design, integrated design and creativity have been continuously strengthened [4,5]. We have been practicing teaching interaction, financial education, learning in the design process. Implement the teaching mode of "large class teaching, group discussions, product-driven”, and “refine concept, creatively start, product formation”. The meaning of "large class teaching, group discussions, product-driven" is the form of teaching organization. The meaning of "refine concept, creatively start, product formation" is the order of teaching content. Through this model, the projects coming from the enterprise design competition will be directly introduced into the classroom. The project design requirements and the design process in accordance with the enterprise product design operation mode will be used to organize the implementation of teaching. The flowchart of the teaching content is shown in Fig. 2.

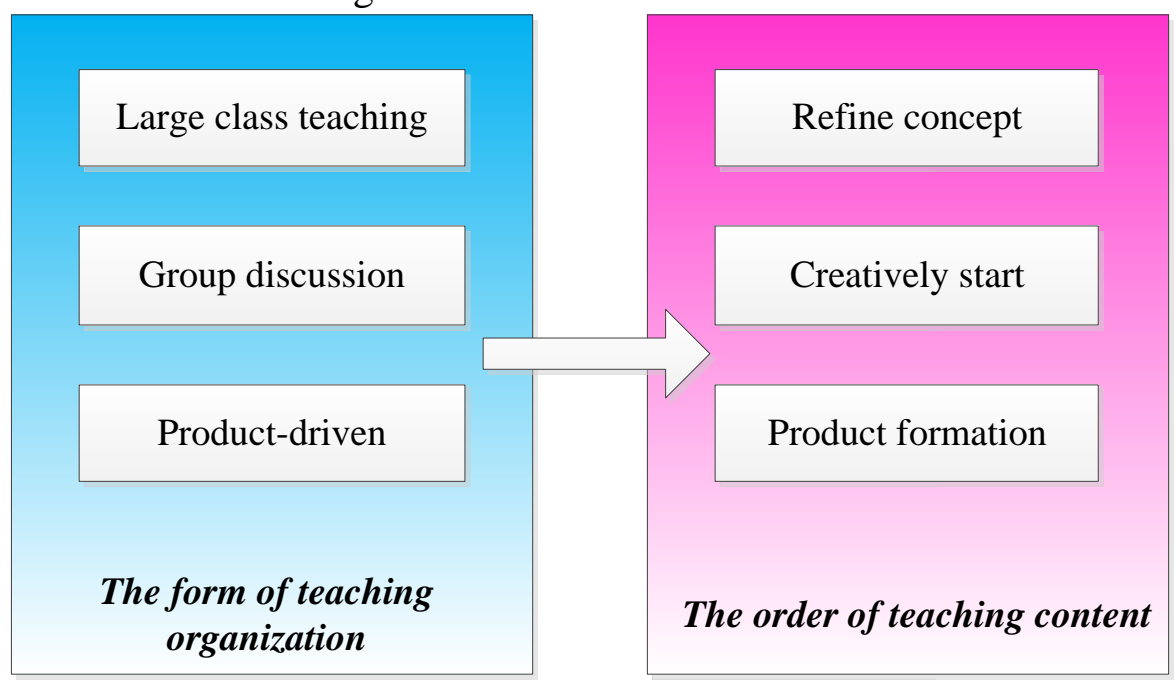

Fig. 2 The flowchart of the teaching content

\section{Comprehensively Use Various Teaching Methods}

Use Heuristic Teaching to Stimulate Students' Creative Thought. Extensive learning and absorbing the advanced experience of product design education at home and abroad, through the course of teaching practice and discussion of inspiring topics to improve the enthusiasm of the students to maximize the mobilization of students for the teaching reform of the sense of participation is conducive 
to student creativity and comprehensive quality training [7]. The proposed course is based on classroom instruction, combined with product design practice teaching. Emphasizing the interaction between teachers and students, is to guide students to learn independently, encourage students to think independently, boldly questioned, guide students to all-round, multi-angle to find the problem and find out the problem. To solve the problem, the traditional teacher-centered classroom teaching model is transferred into student-centered teaching mode. Giving full play to the subjective initiative of students and encouraging students to learn can impel students to master design projects related to design materials, product structure and other knowledge content and expand knowledge.

Set up Seminars to Develop Students Self-Learning Ability. The purpose of the symposium is to emphasize students' mastery and application of product design innovation techniques and product design procedures through thematic discussions [8]. According to the functional design theory and the commercial design idea, we design various design schemes and analyze the conceived solutions to discuss the functional system, the structure combination, the technical material, the supporting interface treatment, external form, color, etc., and integrate and focus on the merits of the program, the formation of optimal programs. Learn and master the technical principles, design materials, product structure and other knowledge contained in the project design, expand the knowledge learned in the classroom, cultivate students' creative way of thinking and methods to improve self-learning ability.

Case Teaching Improves Students Comprehensive Analysis. Case teaching is to master the basic theoretical knowledge and design methods, based on the use of the design master of outstanding works, typical cases, the design creativity, design effects of case analysis. Through independent thinking to further, students can enhance their sense of innovation, the design concept and the design method, cultivate the students good work style, the communication ability and the team cooperation spirit. On the one hand, teachers will be successful to design projects or design competition award-winning project analysis, learn and master the design concepts and methods. On the other hand, each student need to design PPT to explain their projects, other students can make comments on the program. Through this learning interaction, students can learn from each other and improve the ability to analyze problems.

\section{Improve the Assessment Mode}

In order to improve the enthusiasm of students and teaching effectiveness, in addition to carefully organize teaching content and comprehensively use a variety of teaching methods, the reform of assessment mode is necessary [9].

(1) The process assessment idea is considered. Teaching is a dynamic and continuous process, to achieve an objective, fair and scientific evaluation of the teaching quality and student performance, its evaluation activities should be throughout the teaching process. Its approach is to make score to students in the design process of the draft plan, modeling and the effect map, and then accumulated.

(2) The method of network evaluation in industrial design competition is introduced into the teaching assessment. Students need to upload the design work to the course resource website. The evaluation team consist of three or more people, including teachers. At the same time, an evaluation index system is established to evaluate the innovation, science, application and expressiveness of design.

\section{Develop and Construct the Teaching Resources Library}

The construction of the course teaching resource library is the important link of the d the education information development. The research of the product design method and the procedure course resources construction has the vital significance to the curriculum information construction and the teaching effect enhancement. We use the method of integrable ware to construct the product design 
method and procedure course resource library. Through the joint efforts of the course group, the construction of the resource library is finished. From the overall structural arrangement, the course resource library follows the train of thought that "the purpose of knowledge structure design is not only beneficial to reflect the level system of teaching content, but also to the individualized learning and the students' divergent thinking". The curriculum resources are divided into five modules: course learning, teaching interaction, learning resources, design style, and friendship links. Each module is subdivided into many small modules. In order to organize the rich and colorful learning content, form reusable digital components, and facilitate the students to split and reconstruct, the designers have designed the curriculum resource library systematically.

This resource library contains the following five aspects:

(1) Course study: This part contains the content of this course, a total of seven chapters, each chapter contains PPT documents with lectures, lesson plans, the chapter exercises, exercise answers, download resources and so on.

(2) Teaching interaction: Through this module, students can upload their own design work, teachers can design works on-line evaluation and assessment for the relevant issues discussed.

(3) Learning resources: including works appreciation, student works and teaching video content.

(4) Design style: This part describes the design history of the various design styles, including the United States and other five industrial design developed countries, industrial design style and characteristics of the design history of the famous master and his works.

(5) Links: This part provides the well-known industrial design website and domestic university website links to facilitate the search for relevant information, learn about the latest development of industrial design overview.

The part of the interaction between curriculum and teaching is mainly used for teaching, learning resources, design style, friendship links for students to self-reference. The library is rich in content, which can be used for teaching, while students can learn, add some extra-curricular knowledge, understanding of domestic and international design style, enjoy some good works, in order to improve student design and innovation. Moreover it can take full advantage of this network, a modern tool, for students to conduct extracurricular communication.

\section{Conclusions}

Through the research of teaching content, teaching method and method reform, practice teaching mode and teaching evaluation, we have explored the new teaching model of product design method and program course, and achieved better teaching result. The course resource library has won the National Multimedia Courseware Competition second prize. Through the teaching of this course, the students of industrial design specialty in our school have improved their creativity and creativity, and their hand-painted modeling ability has been strengthened. The design works are closer to the reality of the enterprise, and have been recognized by the enterprises and the society.

\section{Acknowledgements}

This research is supported by the Reform program of Hebei Education Department (2016GJJG319)

\section{References}

[1] Yan Bo, Yan Chunyan, Ding Zhizhong, FengYajuan. Reform and research of experimental teaching on course group of product design. Research and Exploration in Laboratory, 2012, 31(5): p. 128-131.

[2] XuHuizhen, Qin Jian. Reform and practice of the course “product design” based on project 
approach. Journal of Ningbo Institute of Education, 2011, 13(5): p. 11-14.

[3] Li Yongfeng. Exploration of product design practical course's teaching of industrial design major. Higher Education Forum, 2010, 4: p. 97-99.

[4] Wu Qishu. Ningbo Higher product design course teaching and research based on regional products clusters. Journal of Zhejiang Business Technology Institute, 2016, 15(1): p. 73-77.

[5] Liu Yongzhan, Liu Jinghua. Research on the practice instructing for the product design curriculum under the university-industry collaboration mode. Journal of Graphics, 2013, 34(5): p. 88-92.

[6] Shi Lin. The research on the hierarchy theory of design management application in the product design teaching and practice. Journal of Zunyi Normal College, 2016, 18(1): p. 154-156.

[7] Zhao Weidong. Discussing the design of the teaching methods based on the concept of green design product. Ecological Economy, 2014, 2: p. 293-295.

[8] Liu Liyuan. Dual-effects of teaching reform of products design courses. Journal of Ningbo University, 2016, 38(3): p. 97-100.

[9] Jiang Dejun. Methods of product design and teaching reform and practice of the program curriculum. Journal of Hunan Institute of Engineering, 2014, 24(3): p. 91-93. 